\title{
Preparing Teachers for Special and Inclusive Education: Applicability of a Model Developed in New Zealand to the English Speaking Caribbean
}

\author{
Marcia Pilgrim \\ 28 Violet Row, Sunset Crest, St. James, Barbados, BB 14015. \\ Tel: 12464320111 Email: marciarosepilgrim@gmail.com
}

Garry Hornby (corresponding author)

College of Education, University of Canterbury, PB 4800, Christchurch, 8140, New Zealand

Tel: 12464320111 Email: garry.hornby@canterbury.ac.nz

Received: January 17, 2016 Accepted: January 21, 2016 Published: January 31, 2016

doi:10.5296/jet.v3i1.8963ＵRL: http://dx.doi.org/10.5296/jet.v3i1.8963

\begin{abstract}
The focus of this article is to discuss the issue of teacher preparation for special and inclusive education in the English speaking Caribbean. The article suggests how teacher preparation for special and inclusive education in the Caribbean could be improved by the implementation of a competency-based, e-learning training program that was developed in New Zealand. The New Zealand training program is described and a brief summary of findings of a study evaluating the effectiveness of the program is presented. Finally, the article highlights how the New Zealand program can be translated into the Caribbean context.
\end{abstract}

Keywords: special education, inclusive education, learning and behavior difficulties, competency based training, e-learning

\section{Introduction}

A critical factor in bringing about effective special and inclusive education practice in schools is the training and ongoing professional development of teachers in the education of children with special educational needs and disabilities (SEND). This includes both teachers in mainstream schools as well as those in specialist support and teaching roles, such as resource teachers and special school teachers. Providing this training and ongoing professional development of teachers is particularly challenging in the English speaking Caribbean, as in 
many other developing countries, because of the limited resources available, but also because of the difficulties involved in providing training to widely geographically spread populations.

This article will describe a model of teacher training for SEND that was developed in New Zealand which is flexible enough to address these challenges. The model utilizes mainly on-line learning in order to make the program available cost effectively to teachers who are widely geographically spread. Findings from a survey of specialist teachers graduating from the New Zealand program will be used to demonstrate the potential effectiveness of this training method. It is proposed that a similar program could be implemented in the English speaking Caribbean in order to facilitate the implementation of effective special and inclusive education practices in schools.

The issue of providing training for teachers working with children with special educational needs and disabilities (SEND) has long been a concern across countries of the English speaking Caribbean (Hornby, Hall, \& Ribeiro, 2000; Pedro \& Conrad, 2006). For example, Pedro and Conrad (2006) report that, in the late 1980s, the Ministry of Education in Trinidad and Tobago hosted a series of workshops on special education sensitization, supported by the Canadian International Development Agency and provided by the University of Manitoba. These workshops were very well received and highlighted the need for more training for teachers in the area of special educational needs. Then, in 1989, the Trinidad and Tobago Special Education Association and Teachers' Association launched Certificate and Diploma programs in special education that were taught by the University of Sheffield. These programs were responsible for training over 300 teachers in special education in the following years. Subsequently, Masters and Doctoral level programs were added.

Some progress was also made on special education training in Barbados in the late 1990s following publication of the 'White Paper on Education Reform - Each One Matters'. This spelt out the Ministry of Education's policy in relation to special needs education and other education issues of the day (Ministry of Education, 1995). The White Paper led to the appointment of an international consultant on special educational needs for a two year term (1997 and 1998), during which training on SEND was provided to teachers in mainstream schools and a certificate course in special education was offered at Erdiston Teachers College. In addition, a Masters degree program in special education was established at the UWI Cave Hill campus with a cohort of 25 teachers, who had their fees paid by the Ministry (Hornby \& Neblett-Lashley, 1998). Resources for mainstream teachers and for parents of children with SEND were produced and distributed (Hornby, 1998, 2000) and a series of workshops were held on Saturdays for parents of children with SEND.

In the past 15 years, due to various economic downturns and a lack of government focus on children with SEND, there has been limited training available for teachers of these children in either mainstream or special schools in Barbados. Recently, a Masters Degree in Inclusive Practices, which focuses on children with special educational needs, has begun to be offered at UWI Cave Hill, but with the government not paying students' fees enrolment has been limited. Some Barbadian teachers have been able to obtain scholarships to study special or inclusive education at overseas universities. Also, there are a few on-line Masters programs in 
special education being offered by overseas universities, which teachers in the Caribbean can enroll in, but these are very expensive, so few teachers have undertaken these programs. The current situation in Barbados is highlighted by a recent survey of four special education facilities, two special schools and two special units in mainstream schools, which found that most of the teachers were not trained in special education (UNICEF, 2014).

So it is clear that there is a glaring need for a program which provides training for specialist teachers of children with SEND to work in mainstream schools, as well as in special education facilities, to be made available in Barbados and probably also across the entire English speaking Caribbean. This training program needs to be in a format that can be accessed by teachers throughout the English speaking Caribbean. It needs to be economical to provide and focused specifically on the needs of teachers working in the Caribbean context.

In a climate in which universities are under pressure to increase quality and lower costs, e-learning has the potential to achieve these goals (Garrison, 2011). The e-learning framework enables large groups of students to be effectively managed (Garrison \& Vaughn, 2008). However, Fishman et al. (2013) point out, in their discussion of professional development for teachers, that planning and implementing effective programs involves substantial costs whether the learning platform is online or face-to-face. Whether online learning is the more cost effective option or not is dependent on the context in which the learning is taking place. For example, a large program that is intended to run repeatedly, and is conducted over a relatively long period of time and engages a widely geographically distributed group of participants will be delivered more cost effectively online than in a face-to-face setting.

Within a range of teacher education and professional development training contexts, delivery using an e-learning format is generally considered as effective as traditional approaches. Several studies considering the professional development of teachers of students with SEND have shown positive results using e-learning approaches. For example, in their study of an online professional development training program for teachers of students with autistic spectrum disorders, Rakap et al. (2014) found that training delivered entirely online was effective in helping teachers to develop and improve the knowledge, competencies and skills needed to work effectively with students with autism and their families. In another study Thompson et al. (2012) report on the use of e-learning to deliver an introductory special education course to students enrolled in a large teacher training program at a Midwestern university in the USA. Instruction was delivered to students either via face-to-face methods or through online learning. Student satisfaction, achievement and engagement were investigated in both conditions with results suggesting similar outcomes in both conditions.

Based on the above discussion it is considered that a potential model for developing and providing a program of special education training that is suitable for the English speaking Caribbean is the one that is now used for training specialist teachers throughout New Zealand, which is described below. 


\section{Training Program for Specialist Teachers in New Zealand}

The Post Graduate Diploma in Specialist Teaching (PGDipST) is a two year part-time program that was established in New Zealand in 2011, and is jointly taught by staff from Massey and Canterbury Universities. The program encompasses seven specialist areas of study: autism spectrum disorder, blind and vision impairment, early intervention, deaf and hearing impaired, complex needs, gifted and talented, and learning and behavior difficulties. In each of these areas of study students are required to complete four courses, one of which is a core course that is taken by students in all seven areas of study, the other three courses are specific to each area of study. The area of study within the program that focuses on learning and behavior difficulties has by far the greatest number of students, and is the focus of this article.

During planning of the various strands of the program, lists of competencies were devised by specialist staff from Massey and Canterbury Universities taking account of information gained from: a national survey of stakeholders in the community; consultation with the Ministry of Education; and, extensive advisory group consultation, including an advisory group for each study area, a reference group focusing on Māori (the indigenous people of New Zealand) and an international advisory group (Bevan-Brown et al., 2010). Key documents, for example, the Registered Teacher Criteria (New Zealand Teachers Council, 2010), cultural competencies (Ministry of Education, 2011) and the CEC Standards (Council for Exceptional Children, 2008) were also taken into account. Competencies were organized into competency domains and course content was developed to address those competencies.

The program employs a community of inquiry and inter-professional practice approach within a mainly online learning framework (Bevan-Brown et al., 2010). Participants are required to attend two three-day face-to-face program sessions per year and to participate in online learning over the two years of the program. Students are encouraged to learn with, from and about each other's specialist areas and to collaborate both within and across specialist disciplines. A Moodle-based e-learning site is used as the learning platform for the program. This platform enables a number of applications that include, for example, video introductions, linked readings and videos, quizzes, discussion forums, noticeboards, electronic media such as online video, and assignment submission and marking using e-portfolios

\subsection{Post Graduate Diploma in Specialist Teaching (Learning \& Behavior)}

The PGDipST (L\&B) program aims to support specialist teachers to develop the competencies they need to work effectively with classroom teachers, schools and students as agents of change, thereby improving outcomes for learners. The four courses of the PGDipST (L\&B) addressed 51 competencies and were delivered over a period of two years of part-time study, with most students working four days and having one study day per week. The courses were: Theory and Foundations of Learning and Behavior Diversity (L\&B); Core Theory and Foundations of Specialist Teaching (Core); Evidence-Based Inter-professional Practice (EBIP); and, Practicum for Learning and Behavior (Practicum). 
The L\&B course was completed in the first year of study and was the course specifically focused on specialist teachers working with children with mild to moderate learning or behavioral difficulties. This course was an advanced study of the theoretical and research-based foundations related to understanding, assessing and providing for learners who have special needs in the area of learning and behavior. L\&B course content was organized into six competency domains, or areas of study. These were concerned with: the nature of learning and behavior diversity, individual evidence-based assessment and intervention, small-group evidence-based assessment and intervention, whole-class evidence-based assessment and intervention, school-wide evidence-based systems and interventions, and effective practice for specialist teachers.

The Core course was compulsory for students in all seven areas of study within the program. The course, also completed in the first year of study, was an advanced study of generic issues relevant to professionals working in all seven areas. Core course content was divided into six competency domains. These were: professional knowledge, assessment practice, evidence-based practice, inter-professional practice, cultural responsiveness, and reflective and ethical practice.

The EBIP course was completed in the second year of study and focused on an examination of evidence-based practices and professional practices of specialist teachers. This course was divided into three domains. The first two domains, one on evidence-based practice and the second on inter-professional practice, were generic and completed by students in all seven strands of the program. The generic nature of these first two domains enabled students to work collaboratively across speciality areas on a collaborative consultation and partnership project. In the third domain students applied what they had learned in the generic domains to their practice as learning and behavior specialists.

The Practicum course was also completed in the second year of study and was situated in the professional practice of students who were working as specialist teachers while they completed the program part-time. Students were supported in this practicum by course tutors, mentors in the field of specialist teaching and peers who were also undertaking the program. Following reflection on their practice students planned learning activities to meet their learning needs and goals in line with indicators developed from the New Zealand Registered Teacher Criteria. The practicum course comprised seven competency domains. These focused on: professional, reflective and ethical practice; cultural responsiveness; professional knowledge and ongoing professional development; inter-professional practice; evidence-based assessment; evidence-based instruction and strategies; and case management for specialist teachers.

The 51 competencies included in the four courses of the program can be grouped into five overall themes. These are: assessment and intervention; collaboration and consultation; cultural responsiveness; professional and ethical practice, legislation, policy and curriculum documents; and professional development, human development and learning issues. These are listed below. 


\subsection{Assessment and Intervention}

- Demonstrate an understanding of the nature and extent of learning and behavior difficulties and interventions to meet the needs of students who experience difficulties with learning and behavior.

- Demonstrate knowledge and skills in planning, adapting, implementing and critically evaluating ecologically valid, evidence-based, culturally appropriate individual assessments and interventions for students who experience difficulties with learning and behavior.

- Demonstrate knowledge and skills in planning, adapting, implementing and critically evaluating ecologically valid, evidence-based, culturally appropriate small group assessments and interventions for addressing learning and behavior difficulties.

- Demonstrate knowledge and skills in planning, adapting, implementing and critically evaluating ecologically valid, evidence-based, culturally appropriate whole class assessments and interventions for addressing learning and behavior difficulties.

- Demonstrate knowledge and skills in planning, adapting, implementing and critically evaluating ecologically valid, evidence-based, culturally appropriate school-wide systems and interventions for addressing learning and behavior difficulties.

- Demonstrate knowledge of evidence-based and effective teaching/learning practices.

- Critically evaluate resources and intervention strategies.

- Critically discuss and evaluate curriculum and program adaptations and solution/ strengths-based interventions.

- Demonstrate knowledge of assessment models and practices.

- Critically evaluate assessment approaches and tools.

- Discuss and compare assessments practices across specialist areas.

- Identify and critically analyze evidence-based practices in the area of learning and behavior including special and inclusive education.

- Conceptualize, plan and implement an appropriate learning program.

- Gather, analyze and appropriately use, assessment information which has been gathered formally and informally.

\subsection{Collaboration and Consultation}

- Demonstrate understanding of inter-personal competencies needed for working effectively with parents, extended family, teachers, other school staff and professionals not based in schools.

- Demonstrate an understanding of the concept of teacher learning and the knowledge and skills for assisting teachers and principals to create positive learning environments.

- Demonstrate knowledge of collaborative and consultative models of working and strengthening partnerships.

- Share professional knowledge and skills to learn with, from and about specialist areas.

- $\quad$ Reflect on and contribute to communities of learning and practice.

- Demonstrate knowledge and understanding of principles and practices of learning with 
from and about other specialist areas.

- Critically discuss the values, skills and attitudes needed for inter-professional practice.

- Collaborate on an inter-professional case study.

- Critically reflect on issues relating to forming partnerships with professionals and stakeholders.

- Show leadership that contributes to effective teaching and learning.

- Establish and maintain effective professional relationships focused on the learning and well being of children.

\subsection{Cultural Responsiveness}

- Demonstrate an understanding of the concept and role of culture.

- Reflect on own cultural values, practices and beliefs.

- Demonstrate an understanding of Māori thinking and theorizing.

- Critique the influence of the majority culture on the New Zealand education system.

- Demonstrate an understanding of the concepts of biculturalism and multiculturalism.

- Critically discuss and apply Māori and multicultural concepts and practices across Specialist Teaching areas.

- Demonstrate a commitment to bicultural partnership in New Zealand.

- Respond effectively to the diverse language and cultural experiences, and the varied strengths, interests and needs of individuals and groups of children.

- Work effectively with the bicultural context of New Zealand.

\subsection{Professional and Ethical Practice and Legislation, Policy and Curriculum Issues}

- Demonstrate an understanding of the specialist teacher role and its links to other learning and behavior initiatives.

- Demonstrate knowledge and skills in developing, delivering and evaluating specialist teacher operational processes.

- Demonstrate knowledge and skills in becoming an ethical and reflective practitioner.

- Demonstrate knowledge and skills in using the code of ethical practice for various Specialist Teaching areas (eg Teachers Council Ethical Guidelines).

- Critically discuss legislation, policy and curriculum documents across Specialist Teaching areas.

- Critically review historical and current perspectives on special and inclusive education, disability and diversity. 
- Consult, collaborate and reflect on IEP or equivalent across specialist areas.

- $\quad$ Understand and apply evidence-based frameworks relating to inclusion.

- Demonstrate a commitment to sustainable practice.

- Demonstrate a commitment to promoting the well - being of all learners.

- $\quad$ Promote a collaborative, inclusive and supportive learning environment.

- Maintain effective record keeping systems.

\subsection{Professional Development, Human Development and Learning Theory}

- Demonstrate knowledge of human development and learning theories.

- Consult and collaborate on inter-professional implications of theories of learning and development.

- Demonstrate in practice, knowledge and understanding of how children learn.

- Demonstrate a commitment to ongoing professional learning and development of personal professional practice.

- Use critical inquiry and problem solving effectively in professional practice.

\section{Evaluation of Specialist Teacher Training in New Zealand}

This section of the article provides a brief summary of the findings of a study of the first cohort of specialist teachers who graduated from the Post Graduate Diploma in Specialist Teaching (Learning and Behavior). Two key questions that were addressed in the study were:

1) To what extent did participants consider that the competencies addressed in the program were important to their professional work?

2) To what extent did participants consider that the program has enabled them to develop the prescribed competencies?

\subsection{Participants}

Of the 81 graduates who successfully completed the Postgraduate Diploma in Specialist Teaching (Learning and Behavior), 42 graduates participated in the study, which represents a response rate of $52 \%$. Most participants were 40 years of age or older with none being 29 years or younger and two being older than 60 years. All participants had experience teaching students with learning and behavioral needs, with 20 having less than ten years experience and 22 having more that 10 years experience. At the time of completion of the survey, all participants worked within the primary school sector, with 26 also working in secondary schools and two working in special schools or special units in mainstream schools.

\subsection{Procedure}

An online questionnaire survey was administered using Survey Monkey. Part one of the survey comprised ten demographic questions, such as age and years of experience. Part two 
required participants to consider each of the competencies in the four courses of the program and rate their responses to the following two questions on a five point Likert scale:

1) To what extent is this competency important to your professional work?

2) To what extent did the course enable you to develop this competency?

The two end points were labeled on the scale with $1=$ minimally important/enabled and 5 = substantially important/enabled.

\subsection{Findings}

The major finding from this study relevant to the first research question was that, in all four courses of the PGDipST(L\&B), participants considered program competencies to be of high importance to their professional work in the field. Across the four courses of the program all competencies were highly rated for their importance to the professional work of participants. There was a small difference of 0.21 between the mean overall ratings for the course with the highest mean competency importance rating, the Practicum (4.84) and the courses with the lowest mean competency importance ratings, the Core (4.63) and EBIP (4.63). The mean rating for the competencies in the $\mathrm{L} \& \mathrm{~B}$ course was 4.76 . The mean rating for importance of competencies across the 51 competencies in the program was 4.70 on the five-point scale

These findings reinforce the view that achieving close correspondence between competencies addressed in training programs and the needs of professional working environments can be achieved by adopting a competency-based approach to education (Herr et al., 1976; Murray, 2009; Sullivan, 1995). The findings highlight the importance of the process by which competencies are generated, as is emphasized by the Council for Exceptional Children (CEC, 2008) in the USA, whose seminal work, What Every Special Educator Must Know, brought together the views of thousands of professionals in the field.

The major finding in relation to research question two of this study was that participants considered themselves to be well enabled to develop competencies in all four courses of the program. Further, there were only small differences between mean overall ratings for the four courses within the program. The Practicum course gained a slightly higher mean competency enablement rating, and the L\&B course gained a slightly lower mean competency enablement rating. Across the four courses of the program, competencies were all highly rated for how well enabled to develop those competencies participants considered themselves to have been by completing the courses. There was only a small difference of 0.23 between the mean overall ratings for the course with the highest mean competency enablement rating, the Practicum (4.21), and the course with the lowest mean competency enablement rating, the L\&B course (3.98). The mean overall enablement rating for competencies in the both the Core and EBIP courses was 4.19. The mean enablement rating of competencies across the 51 competencies in the program was 4.15 on the five-point scale.

These findings are in line with those of Rakap et al. (2015), whose study reported on the perceptions of 33 special education teachers in the USA with regard to their in-service training program in the field of autism. Results of that study indicated that participants, all of 
whom completed a program comprising four web-based courses that were taught within two semesters over a one-year period, significantly increased the levels of competency in each of the six competency areas of their program.

The findings are also in line with those from another recent study, conducted by Conderman et al. (2013), in which 64 beginning special educators were surveyed about their preparation program at a Midwestern university. Participants were asked how well prepared/confident they felt with regard to 25 competencies using a 4 point Likert scale $(1=$ not prepared/not confident; 4 = very prepared/very confident). Results indicated that participants were confident in areas in which they considered themselves to have been well prepared and vice versa. Mean preparation scores ranged from 2.47 to 3.85 while mean confidence scores ranged from 2.61 to 3.85. Participants reported that the practicum component of the program had the greatest impact on their preparation.

\section{Suitability of the Program for the English Speaking Caribbean}

It is proposed that a similar program to that described above, which was developed in New Zealand, could be made available throughout the English speaking Caribbean in order to provide teachers of children with SEND with training relevant to their needs. Such a program could be developed in order to train specialist teachers for working with children with SEND in special schools and units. It could also be used to provide training for resource teachers or learning support coordinators working with children with SEND in mainstream schools, whether they are based in schools or are itinerant and providing services to a group of schools.

A possible means for providing such training is through the Open Campus of the University of the West Indies. This already offers online undergraduate programs in many subject areas including psychology, sociology, management, social work, early childhood education and secondary education. There are also post-graduate programs in adult and continuing, education instructional design and literacy instruction. Therefore, much of the technology is probably already in place to develop a post-graduate program for teachers of children with SEND.

Developers and tutors of such a program could be selected from qualified professionals and academics throughout the English speaking Caribbean, thereby involving people with a wide range of expertise as well as knowledge of local education systems in the program. In this way, courses could be developed to reflect the educational context of the Caribbean, both in terms of education systems and the training needs of teachers.

Lists of competencies to be addressed in the program can be developed by involving stakeholders across the English speaking Caribbean. This would include lecturers in special and inclusive education from the universities and teachers' colleges, officers from the Ministries of Education, teachers' organizations and parent groups. This will ensure that the competencies to be taught within the program are the ones required by specialist teachers of children with SEND in the region.

Although the online training aspect will be the major focus, students can be encouraged to 
form local study groups within which to discuss online content and share ideas with each other. Such learning support groups were found to be a key factor in enabling students to develop the required competencies in the New Zealand study. This suggests a way to involve local professionals in these study groups, perhaps as facilitators, and in this way build local communities of practice which focus on developing competencies for teaching children with SEND.

The program would be available to qualified and experienced teachers who are either working with children with SEND, in mainstream or special schools and units, or who aspire to do so. The program would be offered part-time over two years so that teachers can complete it while continuing to work. The four courses would be each taught in one semester, so that two courses can be completed in one year, and the four courses completed over a two year period.

All teachers could undertake the Core course first, followed by the Specialist course most relevant to them, either focusing on children with autism spectrum disorder, vision impairment, hearing impairment, multiple disabilities, gifted and talented, or learning and behavior difficulties. They will then take another of the Specialist courses, followed by a Practicum course in the second year of the program.

It is possible that governments will support such a program by paying the fees of teachers who enroll, even if this is on the basis of reimbursement of fees for successfully completed courses. Such programs provide governments with cost effective means of training large numbers to specialist teachers who are widely geographically distributed and facilitate the collaboration and sharing of expertise between the personnel who teach on the programs. A major advantage is that once they are developed and are established such online training programs are relatively cost effective to maintain, so that new cohorts of teachers can undertake the program each year.

\section{Conclusion}

A model of teacher training for special and inclusive education, that was developed in New Zealand, has been described. It utilizes mainly on-line learning in order to make the program available at minimal cost to teachers who are widely geographically spread. Findings from a survey of specialist teachers graduating from the New Zealand program were used to demonstrate the potential effectiveness of this training method. It is proposed that such programs could be implemented in the English speaking Caribbean in order to facilitate the implementation of effective special and inclusive education practices in schools.

\section{Acknowledgements}

The authors would like to thank members of the Post Graduate Diploma in Specialist Teaching team, at Massey University and the University of Canterbury, in particular the directors and coordinators of the program, Jill Bevan-Brown, Alison Kearney, Mandia Mentis and Dean Sutherland, plus Angus Macfarlane and John Everatt, and graduates from the first cohort of the Learning and Behavior strand of the program, who took the time to participate in this research project despite their demanding professional schedules. 


\section{References}

Bevan-Brown, J., Kearney, A., Mentis, M., Sutherland, D., Ward, A., Bridges, S., ... Dharan, V. (2010). Post graduate diploma in specialist teaching: Milestone 2 report (3.1). Retrieved from http://specialistteaching.net.nz/course/view.php?id=11

Conderman, G., Johnston-Rodriguez, S., Hartman, P., \& Walker, D. (2013). Honoring voices from beginning special educators for making changes in teacher preparation. Teacher Education and Special Education, 36(1), 65-76. http://dx.doi.org/10.1177/088840641247 3311.

Council for Exceptional Children. (2008). What every special educator must know: Ethics, standards, and guidelines (6th ed.). Arlington, VA: Council for Exceptional Children.

Fishman, B., Konstantopoulos, S., Kubitskey, B.W., Vath, R., Park, G., Johnson, H., \& Edelson, D. C. (2013). Comparing the impact of online and face-to-face professional development in the context of curriculum implementation. Journal of Teacher Education, 64(5), 426-438.

Garrison, D. R. (2011). E-learning in the twenty-first century: A framework for research and practice (2nd ed.). New York, NY: Routledge.

Garrison, R., \& Vaughan, N. D. (2008). Blended learning in higher education: Framework, principles, and guidelines. San Francisco, CA: Jossey-Bass.

Herr, D. E., Algozzine, R. F., \& Heuchert, C. M. (1976). Competencies of teachers of the mildly handicapped. Journal of Special Education, 10(1), 97-106. http://dx.doi.org/10.1177/002246697601000112

Hornby, G. (1998). Special Needs in Mainstream Schools: Teachers' Handbook. Bridgetown, Barbados: Ministry of Education.

Hornby, G. (2000). A Parent's Guide to Special Needs. Bridgetown, Barbados: Ministry of Education.

Hornby, G., \& Neblett-Lashley, B. (1997). Developing training for teachers of children with special needs in Barbados: Challenges and opportunities. Journal of Education and Development in the Caribbean, 1(2), 163-173.

Hornby, G., Hall, M., \& Ribeiro, M. L. (2000). Special Educational Needs in the West Indies. In C. Brock \& R. Griffin (Eds.), International Perspectives on Special Educational Needs (pp. 205-228). London: John Catt.

Ministry of Education. (1995). White paper on education reform - Each one matters. Bridgetown, Barbados: Author.

Ministry of Education. (2011). Tātaiako: Cultural competencies for teachers of Māori learners. Wellington, New Zealand: Ministry of Education.

Murray, J. (2009) Teacher competencies in the post-method landscape: The limits of 
competency-based training in TESOL teacher education. Prospects, 24(1), 17-29.

New Zealand Teachers Council. (2010). Registered teacher criteria handbook. Retrieved from http://www.teacherscouncil.govt.nz/rtc/index.stm

Pedro, J., \& Conrad, D. (2006). Special education in Trinidad and Tobago: Educational vision and change. Childhood Education, 82(6), 324-326.

Rakap, S., Jones, H. A., \& Emery, A. K. (2014). Evaluation of a web-based professional development program (project ACE) for teachers of children with autism spectrum disorders. Teacher Education and Special Education, 38(3), 221-239. http://dx.doi.org/10.1177/088 8406414535821

Sullivan, R. S. (1995). The competency-based approach to training. (Strategy Paper No. 1). Baltimore, MD: Johns Hopkins Program for International Education in Gynecology and Obstetrics.

Thompson, J. R., Klass, P. H., \& Fulk, B. M. (2012). Comparing online and face-to-face presentation of course content in an introductory special education course. Teacher Education and Special Education, 35(3), 228-242.

UNICEF. (2014). Quality of teaching and learning in the special education setting in Barbados. Bridgetown, Barbados: Author.

\section{Copyright Disclaimer}

Copyright reserved by the author(s).

This article is an open-access article distributed under the terms and conditions of the Creative Commons Attribution license (http://creativecommons.org/licenses/by/3.0/). 